Designing Efficient Order Picking Systems by Combining Planning Problems: State-of-the-art Classification and Review

Peer-reviewed author version

VAN GILS, Teun; RAMAEKERS, Katrien; CARIS, An \& De Koster, René B.M. (2018)

Designing Efficient Order Picking Systems by Combining Planning Problems:

State-of-the-art Classification and Review. In: European journal of operational research, 267(1), p. 1-15.

DOI: 10.1016/j.ejor.2017.09.002

Handle: http://hdl.handle.net/1942/24897 


\title{
Designing Efficient Order Picking Systems by Combining Planning Problems: State-of-the-art Classification and Review
}

\author{
Teun van Gils ${ }^{\mathrm{a}, 1}$, Katrien Ramaekers ${ }^{\mathrm{a}}$, An Caris ${ }^{\mathrm{a}}$, René B.M. de Koster ${ }^{\mathrm{b}}$ \\ ${ }^{a}$ UHasselt, Research Group Logistics, Agoralaan Building D, 3590 Diepenbeek, Belgium \\ ${ }^{b}$ Rotterdam School of Management, Erasmus University, PO Box 1738, 3000 DR \\ Rotterdam, The Netherlands
}

\begin{abstract}
Warehouses deliver labor-intensive services to customers. Underperformance may result in high costs and unsatisfied customer demand. New market developments force warehouses to handle a large number of orders within tight time windows. To cope with this, order picking operations need to be optimized by solving a wide range of planning problems. Optimizing order picking planning problems sequentially may yield a suboptimal overall warehouse performance. Still, previous warehouse planning reviews focus on individual planning problems. This literature review differs by investigating combinations of multiple order picking planning problems. A state-of-the-art review and classification of the scientific literature investigating combinations of tactical and operational order picking planning problems in picker-to-parts systems is presented with the aim of determining how planning problems are related. Furthermore, this literature review aims to find excellent policy combinations and to provide guidelines how warehouse managers can benefit from combining planning problems, in order to design efficient order picking systems and improve customer service. Combining multiple order picking planning problems results in substantial efficiency benefits, which are required to face new market developments.
\end{abstract}

Keywords: logistics, order picking, planning problem interactions, joint optimization, literature review

\section{Introduction}

To fulfill customer requirements and differentiate from competitors, warehouses are confronted with a wide range of challenges while planning their operations. Warehouse activities like receiving, storage, order picking and shipping

${ }^{1}$ Corresponding author. E-mail address: teun.vangils@uhasselt.be (Teun van Gils) 
are critical to each supply chain (Gong \& De Koster, 2011). Among these operations, order picking (i.e. retrieval of items in the warehouse to fulfill customer orders) is the most costly warehouse activity (Marchet et al., 2015). Since warehouses deliver labor-intensive services to customers, underperformance may result in high (labor) costs and unsatisfied customer demand (Wruck et al., 2016). New market developments, such as e-commerce, globalisation, increased customer expectations and new regulations, have intensified competition among warehouses and forces warehouses to handle a large number of small orders within tight time windows (Marchet et al., 2015). The task of managing order picking operations, and assessing the relations among order picking planning problems, is perceived as difficult by warehouse managers $(\mathrm{Gu}$ et al., 2007). Therefore, this study focuses on order picking operations. More specifically, picker-to-parts systems (i.e. the order picker travels along the aisles to retrieve products) are considered, as these systems account for the large majority of all order picking systems in Western Europe (De Koster et al., 2007; Marchet et al., 2015).

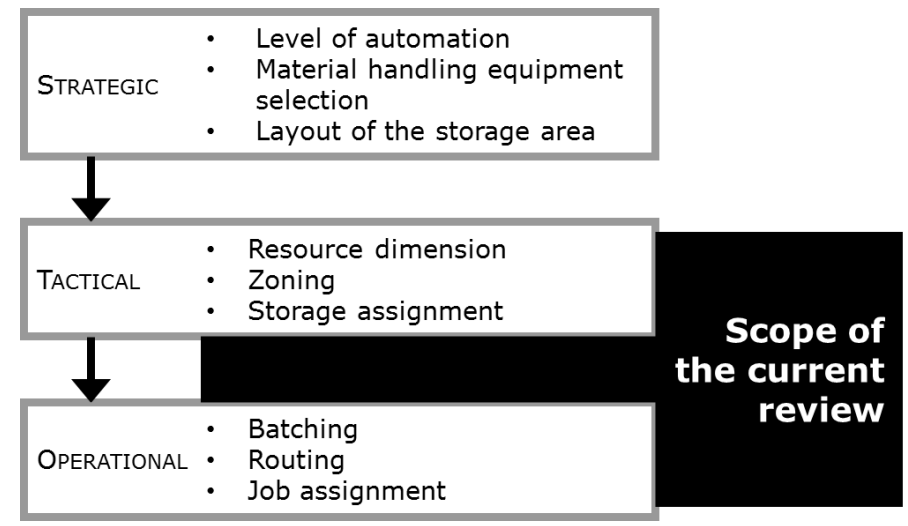

Figure 1: Examples of strategic, tactical and operational decisions.

Decisions to manage order picking can be classified into strategic, tactical and operational decisions (see Figure 1). Strategic management decisions refer to policies and plans for using the resources in order to fulfill the long term competitive strategy. Examples of strategic decisions are the layout of the storage area (i.e., shape, number of warehouse blocks and depot location), as well as the selection of storage systems, in particular the level of automation and the material handling equipment to retrieve items. Typical strategic decisions are discussed in Rouwenhorst et al. (2000), Davarzani \& Norrman (2015) and Marchet et al. (2015). At the tactical level, decisions are taken that impact the medium term. The determination of the resource dimensions, like storage capacity and the size of pick zones, are examples of tactical decisions. Finally, operational decisions typically concern daily operations like batch formation and job assignment. Decisions of operational nature should be considered within the 
constraints set by the strategic and tactical decisions. Van den Berg (1999), and Gu et al. (2007) give an overview of methods and techniques for planning tactical and operational warehouse problems. Gong \& De Koster (2011) focus on tactical and operational decisions, using stochastic methods to model and analyze warehouse operations, while De Koster et al. (2007) focus on layout and control decisions to manage manually operated order picking systems.

Recent literature reviews on warehouse planning, such as Rouwenhorst et al. (2000), Gu et al. (2007), De Koster et al. (2007), Gong \& De Koster (2011) Davarzani \& Norrman (2015) and Marchet et al. (2015) primarily focus on individual planning problems, while concluding that these planning problems are interdependent. Therefore, optimizing each problem separately may lead to a suboptimal solution for the total warehouse. New trends in the logistical industry may require even more efficient picking operations. Multiple order picking planning problems need to be considered simultaneously in order to face these new market developments. This paper differs from previous literature reviews by focusing on how warehouse managers can benefit from combining multiple tactical and operational planning problems in manually operated (picker-to-part) order picking systems.

This paper provides a state-of-the-art review and classifies the scientific literature investigating combinations of tactical and operational order picking planning problems with the aim of answering three research questions. First, based on the classification, we aim to determine how individual order picking planning problems are related and which planning problems should be considered simultaneously in order to optimize the overall order picking performance. Second, by analyzing combinations of planning problems, we aim to identify excellent methods for solving combinations of planning problems that may help managers to take better decisions. Third, while order picking systems in previous research are subject to a large number of assumptions to simplify order picking operations (De Koster et al., 2007; Davarzani \& Norrman, 2015), our classification is used to identify future research directions narrowing this gap between practice and academic research. While Marchet et al. (2015) provide a broad empirical analysis on the selection of order picking systems (i.e. strategic decision focus), this study focuses on combinations of tactical and operational planning problems and how they support new market developments.

The remainder of this paper is organized as follows: Section 2 describes the scope of the review. Section 3 discusses the classification scheme used to categorize publications investigating combinations of order picking planning prob-

lems. The selected publications are classified in Sections 4, 5, and 6 according to defined classifiers. The managerial implications resulting from the literature overview are discussed in Section 7. Finally, Section 8 presents conclusions and opportunities for future research.

\section{Scope of the Review}

This paper reviews and classifies recent order picking planning literature, in particular studies that combine multiple tactical and operational planning 
problems. We do not intend to provide an exhaustive overview of all warehousing literature, but we restrict the reviewed literature by focusing on specific decision areas published in high-quality journals.

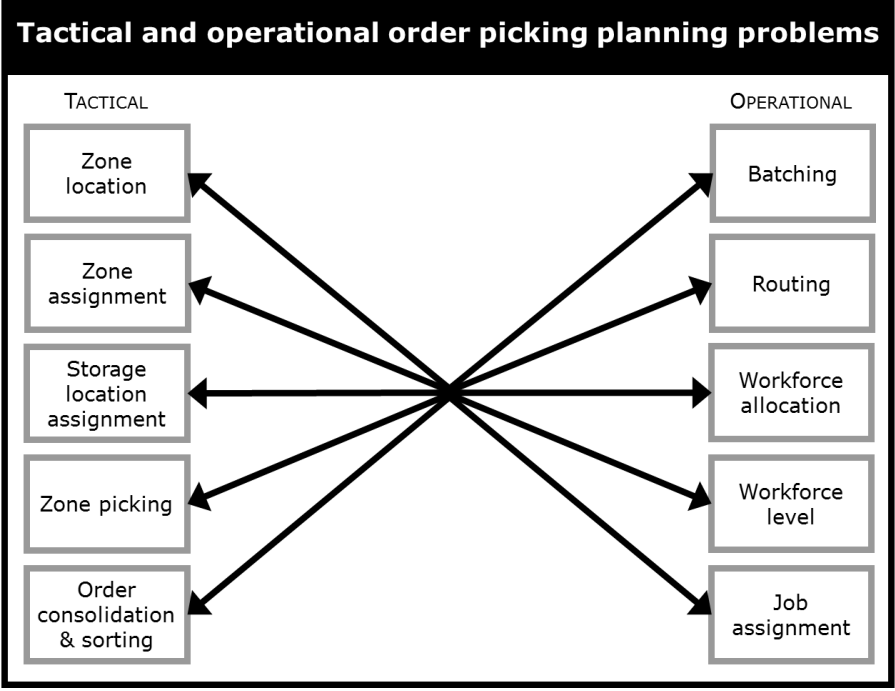

Figure 2: Overview of tactical and operational order picking planning problems.

Figure 2 shows the tactical and operational order picking planning problems that are considered in this review. The overview is based on the planning problems defined by De Koster et al. (2007), complemented with several recent innovative planning problems, such as zone assignment, workforce allocation and job assignment. The reader is referred to Appendix A for an overview and discussion of all order picking planning problems considered in the selection of the literature. Only planning problems that affect an economic goal, such as time or productivity related performance measures, are considered, as these objectives are the most important in any warehouse operation. Consequently, safety and ergonomics issues are beyond the scope of this review. Moreover, warehouse layout (Pohl et al., 2009), as well as other strategic planning problems, such as storage and material handling technology choice (Marchet et al., 2015), depot location (Petersen, 1997), and number of warehouse blocks (Roodbergen \& De Koster, 2001) are mostly fixed in practice, especially in the short and medium term. Therefore, the scope is limited to tactical and operational order picking planning problems, as these problems are expected to be the most relevant to combine.

In order to meet the objectives of the study, two types of publications are considered: articles integrating multiple planning problems and articles examining interactions between planning problems in manual order picking systems. Problem integration refers to formulating and solving two or more planning 
problems jointly, and thus integrating multiple planning problems. Interactions are defined as the joint effect that two or more planning problems have on a performance goal, which can be investigated by considering multiple policies (i.e. solution methods or techniques for organizing a planning problem) for each planning problem and analyzing the effect of these policies on warehouse performance. Consequently, the scope of the review is restricted to articles examining multiple policies for at least two planning problems, since these studies are able to show a potential relation between two or more planning problems. For example a study that combines multiple storage location assignment policies (e.g. random storage and turnover based storage) and multiple routing methods (e.g. traversal, largest gap and optimal routing) is included in the overview, whereas articles assuming a single and fixed routing method in combination with different storage location assignment policies (e.g. Yu et al. (2015) and Guo et al. (2016)) are excluded since these studies are not able to provide knowledge how to benefit from combining multiple planning problems. Furthermore, studies that sequentially optimize multiple planning problems (e.g. Çelik \& Süral (2014) or optimize a single planning problem (e.g. Scholz et al. (2016)) are excluded from the classification as well.

Only articles published in English-language journals with an Impact Factor of at least 0.500 (based on the Impact Factors of 2015 by Thomson Reuters) are considered. Books and conference proceedings are excluded from the classification, as these publications are often preliminary versions of journal publications.

An initial set of articles is selected by searching for at least two of the defined planning problems in articles' titles. The set of articles is extended by considering the citations of the initial set of articles. Each article is evaluated on the investigated planning problems, as well as on the journal selection criteria mentioned above. This search strategy resulted in a final set of 61 representative publications, which are classified in this literature overview. Note that all selected studies focus on traditional picking layouts, i.e. order picking areas consisting of parallel pick aisles and one or more straight cross aisles, while this was not a selection criterion. Combinations of multiple planning problems have not yet been considered for alternative layouts, such as fishbone designs, since these layouts are not efficient in routes consisting of more than two picks (Çelik \& Süral 2014). Most of these studies assume traditional warehouses consisting of a single (i.e. 41 articles) or multiple warehouse blocks (i.e. 20 articles).

Figure 3 illustrates graphically the distribution in time of the selected studies. The number of articles considering the combination of different order picking planning problems has grown strongly in the last decade. $75 \%$ of all considered articles are published in the last decade. While the number of publications on examining a single order picking planning problem was already substantial before 2007, as outlined in De Koster et al. (2007), Gu et al. (2007), Rouwenhorst et al. (2000), and Van den Berg (1999), analyzing multiple order picking planning problems at once has only been a focus since the last decade. The strong increasing line shows the importance of studying multiple order picking planning problems jointly. 


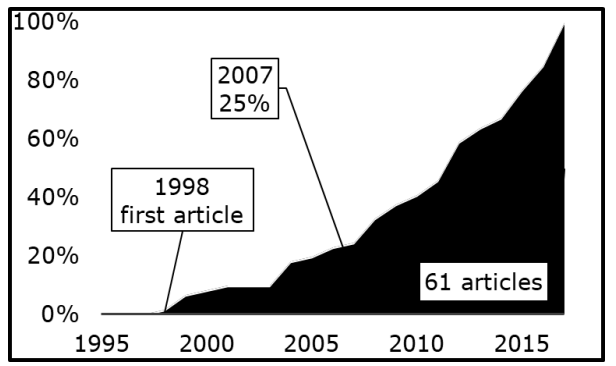

Figure 3: Time distribution of the reviewed articles.

\section{Classification Scheme}

This section introduces a classification scheme to categorize the selected articles. Table 1 lists the classification criteria and features used in this overview paper to categorize the articles. The first classifier divides papers into categories based on the performance measure used to analyze the relation between planning problems with the aim of identifying relevant performance indicators to evaluate the effect of combining planning problems. Next, all 61 considered articles are classified with respect to the research method used to analyze the combination of planning problems. This classification identifies methods for solving combinations of planning problems that may help managers to take better decisions. Finally, articles are classified according to the investigated combination of order picking planning problems in order to identify how planning problems are related and which planning problems should be considered simultaneously to optimize the overall order picking performance. Moreover, the classification identifies how warehouse managers could solve the combination of planning problems while taking real-life issues into account to support order picking processes in practice.

Table 1: Classification scheme

\begin{tabular}{ll}
\hline Classifier & Features \\
\hline Performance measure & Time \\
& Cost \\
& Productivity \\
& Service \\
\hline Research method & Analytical models \\
& Simulation \\
& Mathematical models \\
\hline Combination & Storage location assignment \& routing \\
& Storage location assignment \& order batching \\
& Order batching \& routing \\
& Combinations of other order picking planning problems \\
\hline
\end{tabular}

First, all considered articles are classified according to the order picking per- 
formance evaluation used to analyze the relations between planning problems. Note that only performance measures used to analyze the combined effect of multiple planning problems are considered. Articles are classified according to the performance evaluation dimensions distinguished by Staudt et al. (2015), in particular time, cost, productivity, and service (or quality) related performance indicators. These performance evaluation dimensions are commonly used and help warehouse managers to assess the performance of the operations and to make consequential decisions.

Next, the literature is classified according to the research method used to analyze the effect of combining two or more order picking planning problem or to formulate and solve the integrated problem. The reviewed articles either use analytical models, perform a simulation study, or use mathematical programming to evaluate the combined effect of order picking planning problems. Simulation experiments can be used to determine which combination of factors results in the best order picking performance (Chan \& Chan, 2011) and how these factors influence each other. Analytical models predict the performance by relating the performance variable to the main order picking parameters, such as batch capacity and layout (Caron et al., 1998). Mathematical programming models refer to the set of equations and related mathematical expressions that describe the problem. An objective function and constraints define the overall structure of the problem (Hillier \& Lieberman, 2010).

Finally, the combination classifier categorizes articles according to the investigated combination of order picking planning problems. The overview of Figure 2 is used to classify the articles.

\section{Classification by Performance Measure}

Based on the indicator definitions of Staudt et al. (2015), the reviewed articles are classified according to the performance measure. Table 2 gives an overview of the performance metrics applied to evaluate the combined effect of order picking planning problems. Note that the performance metrics are not mutually exclusive: studies can use more than one performance metric.

All publications, except for Parikh \& Meller (2008) and Tsai et al. (2008), evaluate order picking performance using time related performance indicators, either order picking time (i.e., lead time to pick a set of orders (Van Nieuwenhuyse \& De Koster, 2009)) or earliness/tardiness (i.e., difference between the order completion time and order due time (Henn, 2015) $)$. The process of order picking starts by composing a pick order for which setup time is required. After setting up, the order picker can start traveling to the storage locations (i.e. travel time) and search and pick items (i.e. search and pick time). In case orders are split across zones or batches, these orders should be sorted, consolidated and packed before shipping (i.e. sorting time). Idle time refers to unproductive time, for example time caused by blocking of order pickers within an aisle (Chen et al. 2016), or the time an order spends waiting for a pick batch to be formed (Van Nieuwenhuyse \& De Koster, 2009). Other time components 
Table 2: Overview of the classification by performance measurement.

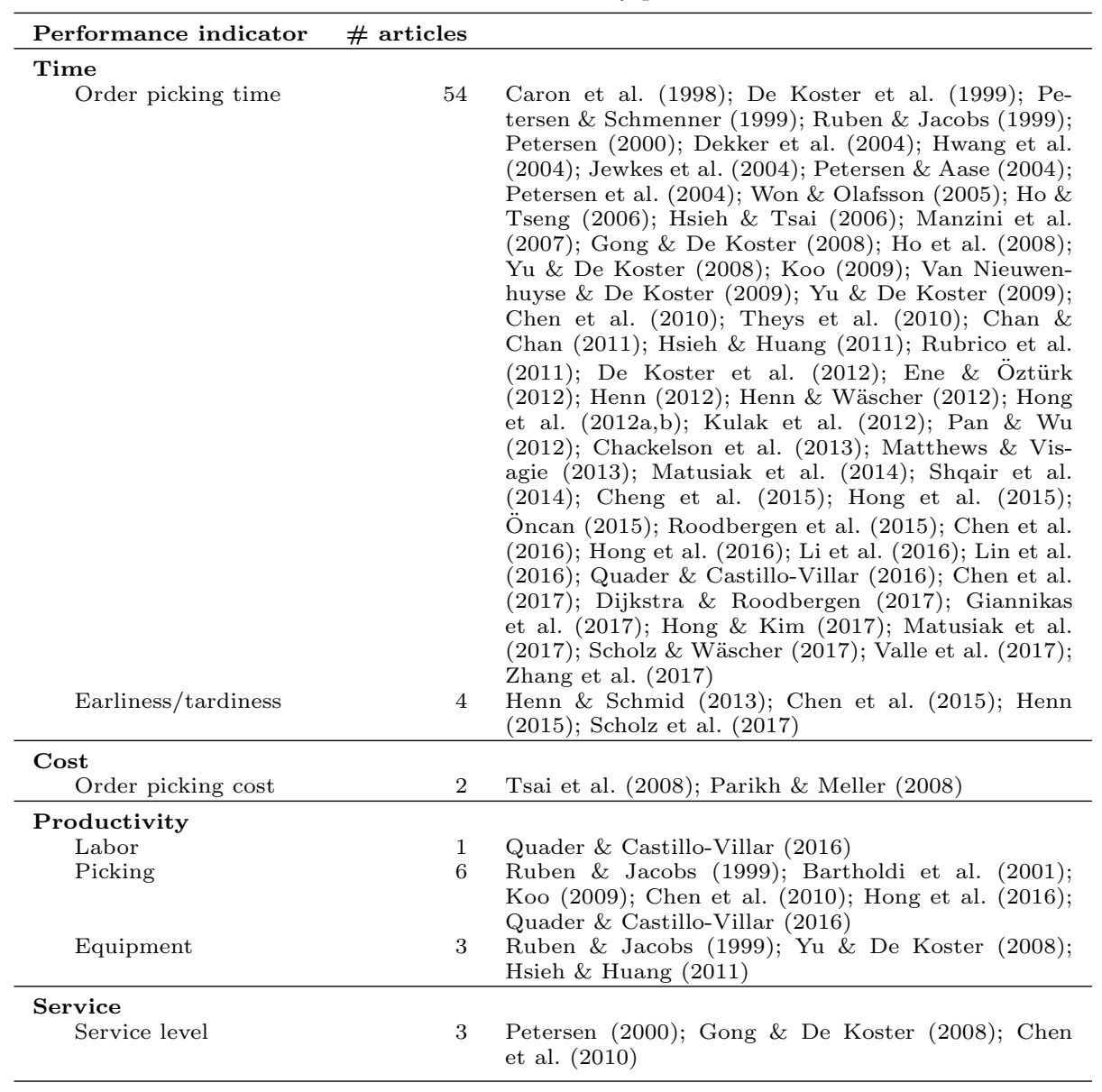

include for example the time transferring orders from picking to sorting operations (Yu \& De Koster, 2009). Thus, the order picking time metric includes setup time, travel time, search and pick time, waiting time, sorting time and other time consuming activities. Besides order picking time, the time performance indicator can be expressed as the earliness or tardiness of orders. As orders should be picked within tight time windows, earliness and tardiness measures are able to evaluate the extent to which these time windows are fulfilled. Thus, earliness and tardiness are especially useful to analyze combinations of operational planning problems. Earliness and tardiness are mainly used to evaluate models that integrate batching and routing in a dynamic context, allowing orders to arrive during the planning period (Tsai et al. 2008, Henn \& Schmid, 2013, Chen et al., 2015; Henn, 2015). Table 3 illustrates the number of articles 
including the components of order picking time. Among all order picking activities, transport is considered as the most time consuming component (Chen et al. 2015). All articles considering time related performance indicators include at least travel time (or travel distance), assuming other time components to be constant. Especially, the effect of picker blocking on order picking efficiency is underestimated in current literature analyzing combinations of planning problems, despite the fact that congestion among workers can be a significant issue in picking areas with high pick densities (Chen et al., 2016). Most articles aim to increase the pick density in order to reduce the travel time by varying combinations of storage location assignment and order batching policies, without taking the picker blocking effect into account (Ruben \& Jacobs, 1999 Hsieh \& Huang, 2011).

In order to efficiently manage order picking operations, time related performance indicators are used in the large majority of articles to evaluate combinations of multiple order picking planning problems. These time consuming components of order picking time can be expressed in terms of costs: all time depending components are multiplied with a fixed cost, such as travel cost per time unit (Tsai et al., 2008). Although order picking time is often used as a proxy for cost, time related measures can additionally inform managers whether due times and operating time windows can be met, while cost performance indicators can include non-time related cost components, such as fixed equipment cost related to a batch or zone order picking system (Parikh \& Meller, 2008), to evaluate different order picking systems.

The productivity metric can be either labor productivity, i.e., ratio of the amount of value-added time and the total picking time (Quader \& CastilloVillar, 2016), picking productivity, i.e. the number of items picked per picker per time interval (Ruben \& Jacobs, 1999), or productivity of the equipment, e.g. the extent to which the picking vehicle capacity is used (Ruben \& Jacobs, 1999. Hsieh \& Huang, 2011). Labor and picking productivity mainly evaluate combinations of zone picking and job assignment (Bartholdi et al., 2001, Koo, 2009 Hong et al., 2016, Quader \& Castillo-Villar, 2016), while equipment productivity has been used to analyze the relation between storage location assignment and order batching.

Finally, service or quality refers to the service level expressed as the percentage of orders that is picked on time (Gong \& De Koster, 2008). The joint effect of combining planning problems on the service level has been analyzed in only three articles, despite the fact that quality is the main service delivered to customers. Warehouses aim to increase the order picking efficiency (i.e. using minimal time to handle more orders), while maintaining a high service level to customers (Chen et al. 2010). The increased time pressure as a result of the e-commerce market developments may increase the chance of pick errors. However, most articles do not take the service level or other quality performance indicators (e.g. pick errors) into account. 
Table 3: Overview of articles including each component of time.

\begin{tabular}{|c|c|c|}
\hline Time component & \# articles & \\
\hline Setup & 18 & 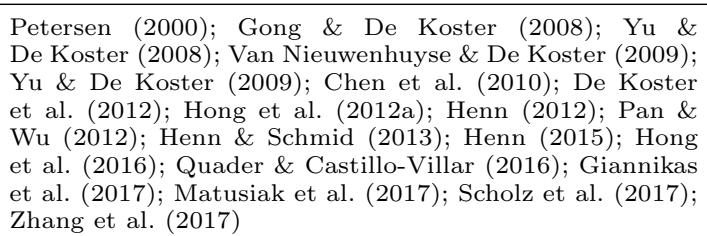 \\
\hline Travel & 58 & 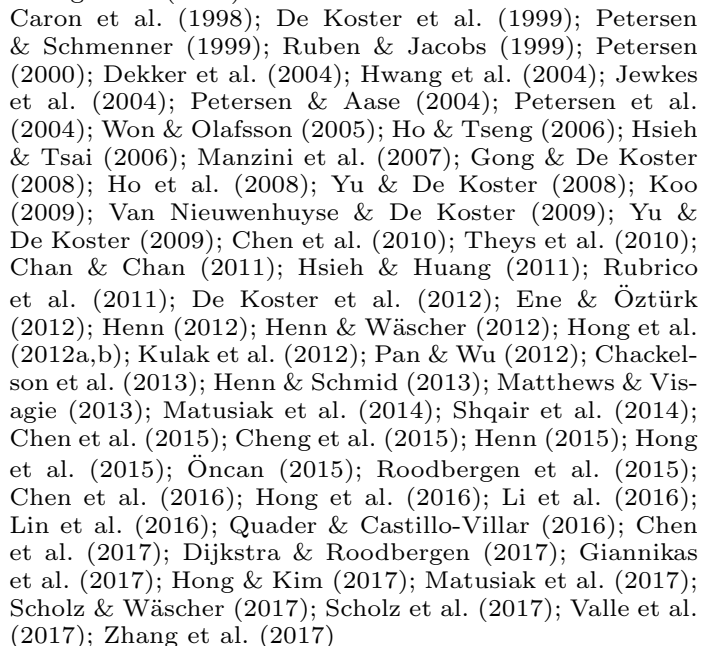 \\
\hline Search \& pick & 26 & 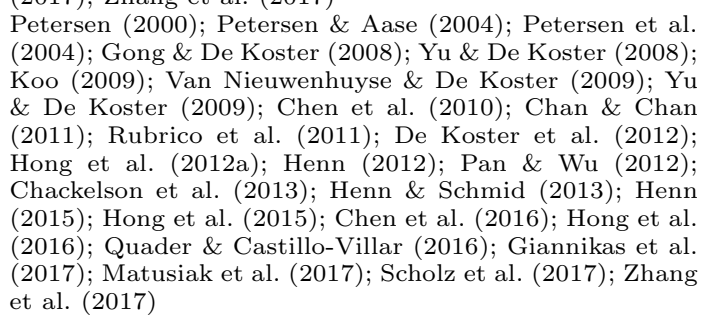 \\
\hline Sort & 4 & $\begin{array}{l}\text { Van Nieuwenhuyse \& De Koster }(2009) \text {; Yu \& De Koster } \\
\text { (2009); Chen et al. (2010); De Koster et al. (2012) }\end{array}$ \\
\hline Idle & 13 & 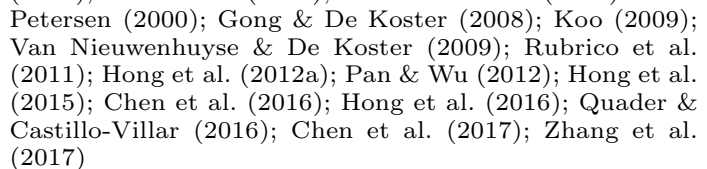 \\
\hline Other & 2 & Won \& Olafsson (2005); Yu \& De Koster (2009) \\
\hline
\end{tabular}

\section{Classification by Research Method}

This section classifies publications with respect to the research method used to analyze or solve the combined problem. The following research methods have been proposed in literature to analyze interactions of order picking policies or to integrate multiple order picking planning problems: analytical models, simulation experiments, and mathematical programming. Analytical models refer 
to a set of mathematical equations that approximate the performance of a system by relating the performance variable to multiple system parameters. Simulation experiments are defined as methods to imitate the system's operations or characteristics with the purpose of conducting numerical experiments to provide insights into the behavior of the system. Mathematical programming models refer to the set of mathematical expressions that describe the problem consisting of an objective function and constraints to define the overall structure of the problem. Figure 4 illustrates the distribution of these research methods in the scientific literature. Simulation is by far the most popular technique to analyze combinations of order picking planning problems, followed by mathematical programming. Appendix B provides an overview of the selected articles according to the investigated planning problems.

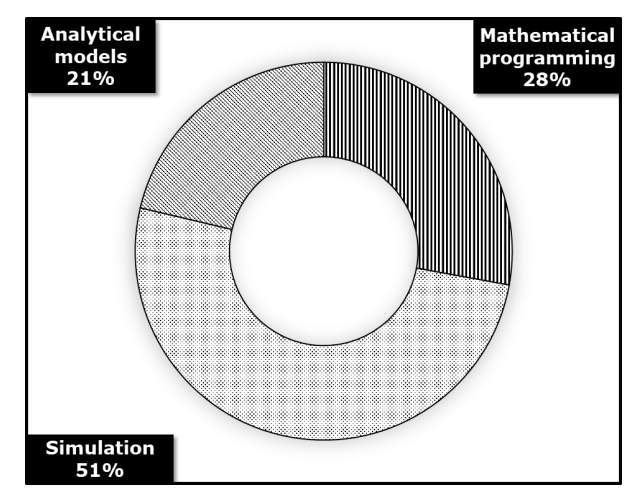

Figure 4: Research method used to analyze the combination of order picking planning problems.

Analytical models have not been considered very often as approach to analyze the impact of combining order picking planning problems. Eleven articles develop an analytical model to evaluate planning problem combinations. An analytical approach for approximating the systems performance has proven to be accurate in evaluating combinations of order picking planning problems, such as storage location assignment and routing (Caron et al., 1998; Hwang et al., 2004), zone location and workforce allocation (De Koster et al. , 2012), and batching and routing (Gong \& De Koster, 2008). This last combination is an application of polling models in the context of order picking: a system of multiple queues of orders accessed by a single or multiple order pickers (Gong \& De Koster, 2008). The proposed analytical models can be used by warehouse managers to predict the system performance under different policies, and to compare these alternatives in a stochastic setting. Analytical models outperform simulations with respect to modeling and computing time. While simulation requires model and scenario development time, a thorough validation process and long runs to reduce the stochastic effect of order generation, 
analytical models can compare policy combinations by simply defining parameter values and evaluating the performance value resulting from the equation. However, analytical models are complex to develop. Consequently, these models often provide a simplified representation of order picking operations investigating a limited number of policy combinations. Under the assumptions of the analytical model, the provided optimal combination of policies can be used as benchmark policies for real-life operations (Van Nieuwenhuyse \& De Koster, 2009).

Table 4: Studies analyzing combinations of order picking planning problems using simulation. ${ }^{\mathrm{a}}$

\begin{tabular}{|c|c|c|c|c|}
\hline & 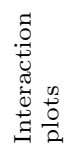 & 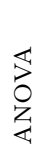 & 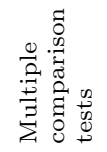 & $\frac{\ddot{d}}{\tilde{0}}$ \\
\hline Petersen \& Schmenner (1999) & • & - & & \\
\hline Ruben $\&$ Jacobs (1999) & & - & • & \\
\hline Petersen $(2000)$ & & - & & \\
\hline Ho \& Tseng 2006 & & - & 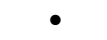 & \\
\hline Hsieh \& Tsai (2006) & & • & • & \\
\hline Manzıni et al. (2007) & - & & & - \\
\hline Ho et al. (2008) & & - & - & \\
\hline Chen et al. (2010) & & & - & - \\
\hline Theys et al. (2010) & - & & & \\
\hline Hsieh \& Huang (2011) & & - & - & \\
\hline Chackelson et al. (2ण13) & - & - & & \\
\hline Shqair et al. (2014) & & • & - & \\
\hline Roodbergen et al. $(2015)$ & & & & - \\
\hline Chen et al. $(\overline{2016})$ & & - & & \\
\hline Quader \& Castillo-Villar (2016) & & - & & \\
\hline
\end{tabular}

${ }^{\text {a }}$ Following studies simulate combinations of order picking planning problems without further analyzing the relation between these problems: De Koster et al. (1999); Dekker et al. (2004); Petersen \& Aase (2004); Petersen et al. (2004); Chan \& Chan (2011); De Koster et al. (2012); Henn (2012); Henn \& Wäscher (2012); Hong et al. (2012a|b); Henn \& Schmid (2013); Henn (2015); Öncan (2015); Chen et al. (2017); Giannikas et al. (2017); Scholz \& Wäscher (2017).

Simulation studies form the largest category of research methods in this literature classification. Just as analytical models, warehouse managers may use simulation results to evaluate the combined effect of multiple order picking planning problems in order to design efficient order picking systems. Simulation models are able to provide a more detailed representation of order picking operations compared to analytical models. A large number of policy combinations can be easily tested once a simulation model has been created. Table 4 summarizes all publications simulating combinations of order picking planning problems. A large number of articles simulate combinations of order picking planning problems without further analyzing the relation between these problems. These studies are mentioned in the footnote of Table 4. In most of these studies, a new solution technique is proposed for solving a single order picking planning problem. This new policy is compared with other policies of the same planning problem, and validated for several policies of other order picking 
planning problems. Their main objective is not to analyze interactions between order picking planning problems. For example, Öncan (2015) introduced an iterated local search algorithm to solve a mathematical programming formulation of the batching problem. This novel batching policy is compared with two savings algorithms and other metaheuristic batching algorithms, and validated by simulating the batching policies in combination with a traversal, return and midpoint routing policy. As the simulation of multiple batching and routing policies provides insights into the effect of combining planning problems, and the heuristic algorithm is only used to solve a single planning problem (e.g., batching (Henn, 2012; Henn \& Wäscher, 2012; Öncan, 2015)), these type of studies are classified as simulation.

More comprehensive studies show interaction plots, and/or perform an analysis of variance (ANOVA) and multiple comparison tests to analyze potential interactions between order picking planning problems. These articles are listed in Table 4. Some papers use interaction plots to show the mean performance values of two order picking planning problems in which the mean values of policies of one planning problem are shown at different levels of the other planning problem. These graphs are used to illustrate interaction effects. A wide range of combinations have been graphically illustrated in literature, such as storage location assignment \& batching (Ruben \& Jacobs, 1999), storage location assignment \& routing (Petersen \& Schmenner, 1999; Manzini et al., 2007; Theys et al. 2010, Shqair et al., 2014), and batching \& routing (Chackelson et al., 2013). ANOVA is the most popular tool to determine the order picking planning problems that have the most significant effect on warehouse performance and confirm whether interactions between order picking planning problems are statistically significant. While lines on the interaction graph can indicate significant interactions, ANOVA is able to prove the statistical significance of interaction terms. All reviewed articles performing an ANOVA analysis test for two-way interactions between planning problems, while Ho \& Tseng (2006), Hsieh \& Tsai (2006), Ho et al. (2008), and Hsieh \& Huang (2011) also test and confirm a statistically significant three-way interaction between storage location assignment, batching, and routing. Additionally, a multiple comparison test can give insight into which policies of an order picking planning problem differ and how policies are ranked under different policies of a second order picking planning problem. For example, Ho \& Tseng (2006) rank different order batching policies under random and turnover based storage location assignment. Performance rankings of the order batching policies are different under random and turnover based storage. This result explains why the two-way interaction between storage location assignment and order batching is statistically significant. Other techniques of Table 4 refer to multi-level factorial analysis (Manzini et al. 2007), data envelopment analysis (Chen et al., 2010), and ranking and selection procedures (Chen et al., 2010, Roodbergen et al., 2015).

Finally, mathematical programming models use mathematical expressions, i.e. an objective function and constraints, to describe a complex problem concisely. The use of mathematical programming as a research method to integrate 
Table 5: Studies analyzing combinations of order picking planning problems using metaheuristics to solve the mathematical programming problem.

\begin{tabular}{|c|c|c|c|c|}
\hline & 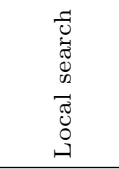 & 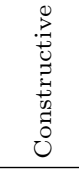 & 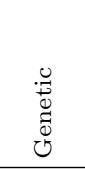 & $\begin{array}{l}\overrightarrow{0} \\
\overrightarrow{0} \\
\overrightarrow{0}\end{array}$ \\
\hline Won \& Olafsson (2005) & $B \& R$ & & & \\
\hline Tsal et al. $(2008)$ & & & $B \& R$ & \\
\hline Ene \& Öztürk (2012) & & & $B \& R$ & \\
\hline Rubrico et al. (2011) & $B \& J$ & & & \\
\hline Kulak et al. $(2012)$ & $B \& R$ & & $B$ & \\
\hline Matthews \& Visagie (2013) & & $R \& J$ & & \\
\hline Matusiak et al. (2014) & $B$ & $R$ & & \\
\hline Chen et al. 2015 & & $R$ & $B \& J$ & \\
\hline Cheng et al. (2015) & & $R$ & & $B$ \\
\hline Li et al. $(2016)$ & $R$ & $R$ & & $B$ \\
\hline Lin et al. 2016 & & $R$ & & $B$ \\
\hline Matusiak et al. (2017) & & $B \& J$ & & \\
\hline Scholz et al. $(2017)$ & $B \& R \& J$ & & & \\
\hline Zhang et al. $(\overline{2017})$ & & $B \& J$ & & \\
\hline
\end{tabular}

$B=$ batching.

$J=$ job assignment

$R=$ routing.

different order picking planning problems is limited. Besides exact solution approaches (Jewkes et al. 2004: Hong et al., 2016: Valle et al., 2017), metaheuristic algorithms are mostly used to solve complex mathematical programming problems in warehouses. Metaheuristic algorithms find a good solution for complex planning problems. As optimizing most single order picking planning problems, such as the order batching problem or the order picker routing problem, have proven to be NP-hard, combining several planning problems will also result in NP-hard problems (Li et al. 2016). Metaheuristics have proven to solve complex planning problems within reasonable computing times. Despite the popularity of metaheuristics for solving large real-life mathematical programming problems (Sörensen \& Glover, 2013), only the integrated problem of batching \& routing, job assignment \& batching and job assignment \& batching \& routing have been solved by metaheuristic algorithms (see Table 5). Planning job assignment, batching, and routing are operational decisions that have to be made frequently, compared to the other defined planning problems. Each of these decisions is taken multiple times each hour. For this reason, warehouses require fast and effective algorithms to fulfill all customer orders.

Metaheuristic algorithms are especially useful for combining order picking planning problems of operational nature. However, integrating planning problems of tactical and operational nature seems to be less meaningful, due to the different time horizons for deciding on both problems. For example, integrating zone location and batching makes little sense, as batches are created multiple times every hour, while the zone location decision is a constant in short term. Simulation and analytical models are more useful to evaluate the efficiency of tactical and operational planning problem combinations. 


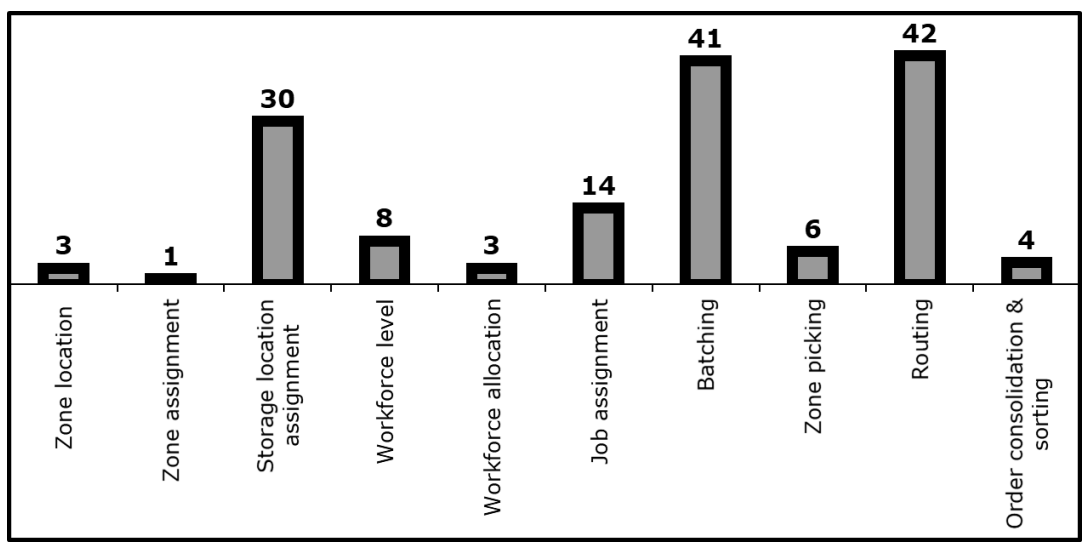

Figure 5: Distribution of the considered order picking planning problems (in number of articles).

\section{Classification by Investigated Combination of Planning Problems}

This section classifies all articles analyzing at least two order picking planning problems simultaneously. Figure 5 illustrates the distribution of tactical and operational order picking planning problems across the reviewed articles. The zoning (i.e. zone location, zone assignment, and zone picking) and workforce (i.e. workforce level, workforce allocation, and job assignment) related planning problems, as well as the problem of order consolidation and sorting have received little research attention in combination with other planning problems. Note that publications examining a single order picking planning problem have devoted little attention to the last mentioned planning problems either $(\mathrm{Gu}$ et al. 2007). Recent publications combining order picking planning problems have strongly focused on storage location assignment, order batching, and routing.

The classification of these studies helps warehouse managers to determine how different individual planning problems are related to each other, at least the combinations that have been investigated, and thus which planning problems should be considered simultaneously (Section 6.1). Furthermore, the performance of policy combinations is analyzed in order to establish several good performing combinations which can be used in practice to optimize order picking performance (Section 6.2).

\subsection{Relations among Planning Problems}

Table 6 provides an overview of all investigated combinations of order picking planning problems. The ten defined order picking planning problems give rise to a large number (i.e. 45) of planning problems combinations. However, only 26 combinations have been investigated to improve order picking efficiency. Only combinations that have been analyzed in at least four research articles are 
Table 6: Overview of investigated combination of order picking planning problems

\begin{tabular}{|c|c|c|c|c|c|c|c|c|c|c|}
\hline & 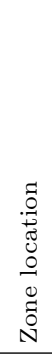 & 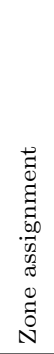 & 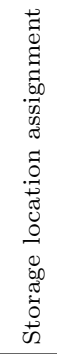 & 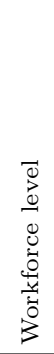 & 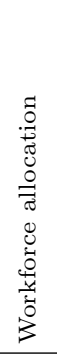 & 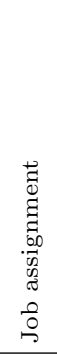 & 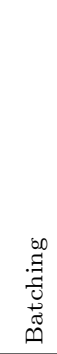 & 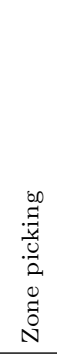 & 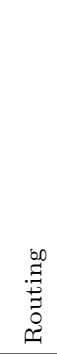 & $\begin{array}{l}0 \\
0 \\
0 \\
0 \\
0 \\
\infty \\
\dot{0} \\
\dot{0} \\
0 \\
0 \\
\overrightarrow{0} \\
0 \\
0\end{array}$ \\
\hline Zone location & & - & 1 & - & 1 & - & 2 & - & - & - \\
\hline Zone assignment & & & 1 & - & - & - & - & - & - & - \\
\hline Storage location assignment & & & & 2 & 2 & 1 & 15 & 1 & 24 & 2 \\
\hline Workforce level & & & & & 1 & 3 & 6 & - & 4 & 2 \\
\hline Workforce allocation & & & & & & - & 2 & - & - & 1 \\
\hline Job assignment & & & & & & & 9 & 5 & 6 & 1 \\
\hline Batching & & & & & & & & 2 & 27 & 4 \\
\hline Zone picking & & & & & & & & & 1 & 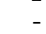 \\
\hline Routing & & & & & & & & & & - \\
\hline Order cons. \& sorting & & & & & & & & & & \\
\hline
\end{tabular}

discussed in this section, in particular storage location assignment \& batching, storage location assignment \& routing, batching \& routing, workforce level \& batching, job assignment \& batching, job assignment \& routing, workforce level \& routing, job assignment \& zoning, and batching \& sorting. Research investigating the effects of combining other order picking planning problems is too limited to draw general conclusions.

Articles analyzing the combination of storage location assignment and order batching are rather consistent about the statistical significance of these two planning problems (Petersen \& Aase, 2004, Ho \& Tseng, 2006, Ho et al., 2008). The storage location assignment policy defines rules for assigning items to locations in the order picking area. The batching policy should take these item location rules into account while creating batches in order to efficiently manage the batching planning problem. The use of item location information in order batching results in significant performance benefits (Ruben \& Jacobs, 1999).

In contrast to the storage location assignment and batching interaction, studies are less consistent about the significance of storage location assignment and routing. In a limited factorial setting, in particular a limited number of analyzed policies, storage location assignment and routing are found to be unrelated (Ho \& Tseng, 2006, Ho et al., 2008: Chackelson et al., 2013). However, other articles do find a statistically significant interaction between storage location assignment and routing, both in single block warehouses (Petersen \& Schmenner, 1999, Manzini et al. 2007), and in multiple block warehouses (Theys et al., 2010 Shqair et al. 2014), as these studies take information about the location of fast moving products into account while composing order picker routes. Furthermore, storage location assignment policies define the pick density within 
aisles, which can result in blocking of order pickers if routes do not account for blocking effects. Thus, whether interactions between storage location assignment and routing exist or not, depends on which policy combinations are evaluated and which order picking time components are taken into account.

Batching and routing problems have been analyzed most often. Several articles analyzing combinations of batching and routing policies reveal that these planning problems are unrelated, both in a single block warehouse (Ho \& Tseng, 2006, Ho et al. 2008) and a multiple block warehouse (Hsieh \& Tsai, 2006), while other studies find significant performance benefits by combining batching and routing in a single block layout (De Koster et al., 1999; Chackelson et al., 2013). These contradicting results may be due to the considered policies, which are more extensive in the studies that find significant effects. The operational planning issues of batching and routing are the most often solved planning problems in warehouses. The construction of batches and the creation of order picker routes are the most appropriate problems to be solved jointly as the processing time of a batch is mainly defined by the length of the constructed route. The integrated problem of batching and routing yields significant performance benefits compared to sequentially solving both problems (Won \& Olafsson, 2005), indicating a strong relation between batching and routing.

Compared to the relations among storage location assignment, batching, and routing, other combinations have not received much research attention. Especially research analyzing the effects of a varying workforce level, that mainly affects the waiting times due to picker blocking (Chen et al., 2016), in combination with other planning problems is scarce. Most articles analyzing workforce level in combination with other planning problems evaluate the combined effect of batching and workforce level, while disregarding picker blocking. Typically, the mean time for picking an order increases as the number of pickers increase, as more order pickers may increase aisle congestion (Ruben \& Jacobs, 1999). However, integrating the picker blocking effects while constructing batches prevents the picking efficiency to decrease as the number of order pickers increase (Hong et al. 2012a).

Similar findings are shown while analyzing workforce level and routing. While considering the effect of picker blocking, certain routing policies (i.e., return routing and optimal routing) yield stronger increased waiting times in comparison with a traversal routing policy in case of increasing the number of pickers (Pan \& Wu, 2012). The mean travel time within an aisle, and consequently the time an aisle is occupied by an order picker, is shorter by applying traversal routes in this case. Waiting times can strongly reduce by considering the picker blocking effects while construction routes (Chen et al., 2016).

Few studies are found that integrate batching and job assignment. In a single order picker system, the job assignment problem is limited to sequencing batches of orders (Chen et al. 2015), while the job assignment problem is more challenging for multiple order pickers as batches need to be assigned to order pickers before sequencing the batches (Henn, 2015). Compared to a due-date first assignment of jobs, the integrated problem of job assignment and batching 
of orders yields improved order picking performance with respect to the tardiness of customer orders (Henn \& Schmid, 2013, Chen et al., 2015: Henn, 2015).

Furthermore, most studies analyzing batching and job assignment additionally consider the picker routing planning problem (Henn \& Schmid, 2013: Chen et al. 2015, Henn, 2015). Different routing policies affect the processing time of batches and may cause tardiness if the order due date is missed. Combining job assignment and straightforward routing policies result in similar performances, while integrating routing and job assignment, and thus finding a (near) optimal combination of routes and job assignments, results in significant performance benefits (Matthews \& Visagie, 2013: Chen et al., 2015).

The combination of zone picking and job assignment is mainly studied by integrating both planning problems in the context of bucket brigades. Bucket brigades zoning is defined as a sequential flexible zone picking policy in which order pickers are assigned to flexible zones and sequentially pick an order (or a batch of orders). In contrast to sequential fixed zone picking, the boundaries of each zone vary dynamically as downstream order pickers take over jobs from their predecessors when they are available. If the most downstream order picker completes his order, this picker takes over the order of the immediately upstream order picker. The latter takes over the order of his predecessor, and so on. The first order picker in line can start with a new order or batch. In this way, the job assignment is formulated as the dynamic assignment of orders to order pickers, integrated in the zone picking problem. The efficiency benefits resulting from bucket brigades show the importance of integrating zone picking and job assignment (Bartholdi et al., 2001, Koo, 2009).

Finally, the effect of sort-while-pick and pick-and-sort in combination with different batching policies is outlined. The sorting policy does affect the batching capacity as sorted orders occupy more space (i.e. sort-while-pick) compared to a pick-and-sort policy (Van Nieuwenhuyse \& De Koster, 2009). Consequently, the performance of batching policies are affected by the applied sorting policy (Hong et al. 2012b, Hong \& Kim 2017). Furthermore, other order picking planning problems, such as workforce level and workforce allocation, additionally affect the performance of sorting and batching policies (Van Nieuwenhuyse $\&$ De Koster, 2009).

\subsection{Excellent Performing Planning Problem Combinations}

As recent literature has mainly focused on three order picking planning problems in order to improve the order picking efficiency by combining planning problems, this section establishes several excellent performing policy combinations divided into combinations of these three planning problems: storage location assignment \& batching (Section 6.2.1), storage location assignment \& routing (Section 6.2.2), and batching \& routing (Section 6.2.3).

\subsubsection{Storage Location Assignment and Order Batching}

Due to the different planning horizons of storage location assignment (tactical) and order batching (operational), literature has focused on analyzing the 
relation between both planning problems. Efficient combinations of storage location assignment and order batching can be achieved by incorporating location information of fast moving items, defined by the applied storage location assignment policy, into the creation of batches. For example seed rules minimizing the number of aisles are preferred in combination with within-aisle turnover based storage location assignment. As fast moving items are assigned to the aisles closest to the depot, batches should be created with the objective of minimizing the number of aisles visited. Selecting the order with the smallest number of picking aisles to visit as seed order and adding orders to the seed that minimizes the number of additional aisles that an order picker needs to visit to complete the batch, in combination with within-aisle storage, outperforms other seed batching policies (Ho \& Tseng, 2006).

Several more sophisticated batching algorithms have proven to increase the order picking performance in combination with within-aisle turnover based storage location assignment, both in a static (i.e. all orders known in advance) (Hsieh \& Huang, 2011, Henn \& Wäscher, 2012), and a dynamic (i.e. real time order arrival) context (Henn, 2012). Most studies only consider random and within-aisle storage in combination with these complex batching policies, which may be explained by the fact that straightforward batching algorithms (e.g. FCFS and seed batching) in combination with within-aisle storage outperform other batching and storage policy combinations (Ruben \& Jacobs, $1999, \mathrm{Pe}-$ tersen \& Aase, 2004 Chen et al., 2010). Disregarding aisle congestion, metaheuristic batching algorithms in combination with within-aisle storage is the current best known storage location assignment \& batching combination assuming a single depot in the pick area.

\subsubsection{Storage Location Assignment and Routing}

Figure 6 illustrates several good performing combinations of storage location assignment policies and straightforward routing policies. In order to reduce order picking travel distance, within-aisle turnover based storage location assignment is preferred while using traversal routing. Since the goal is to reduce the number of aisles visited, fast moving items are assigned to the aisles closest to the depot. Return routing is preferred in combination with across-aisle storage classes, because the aim is to reduce the travel distance within aisles (Caron et al. 1998). Furthermore, the combination of the perimeter storage and the largest gap routing policy on average results in shorter travel times compared to the two previously discussed combinations. Since fast moving stock keeping units (SKUs) are stored along the periphery of the warehouse blocks and largest gap routes tend to follow the periphery of the order picking area, this policy combination increases the order picking performance (Petersen \& Schmenner, 1999).

Because of simplicity, these straightforward routing heuristics are often used in practice, despite the efficiency benefits of following (near)optimal routes. Optimal routes in combination with within-aisle storage location assignment outperform all other combinations of storage location assignment and routing (Petersen \& Schmenner, 1999, Petersen \& Aase, 2004, Theys et al., 2010). How- 


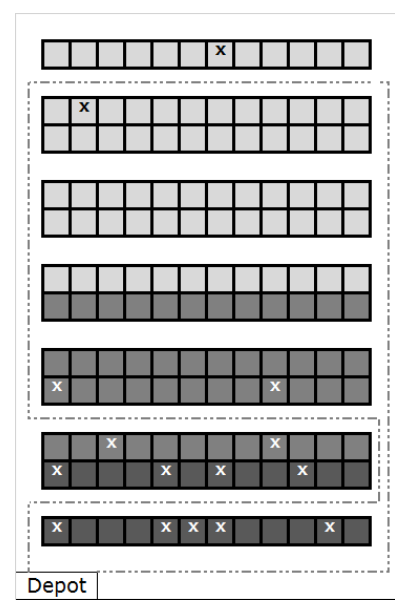

(a) Within-aisle - traversal.

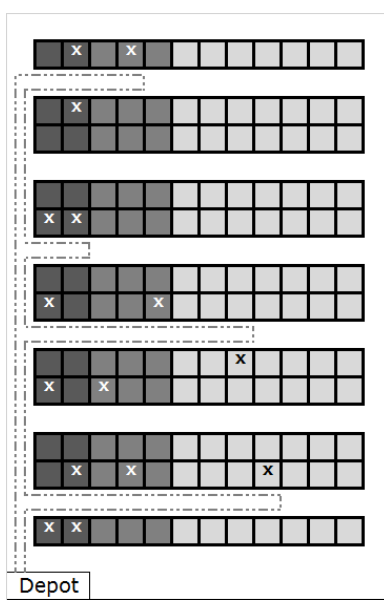

(b) Across-aisle - return.

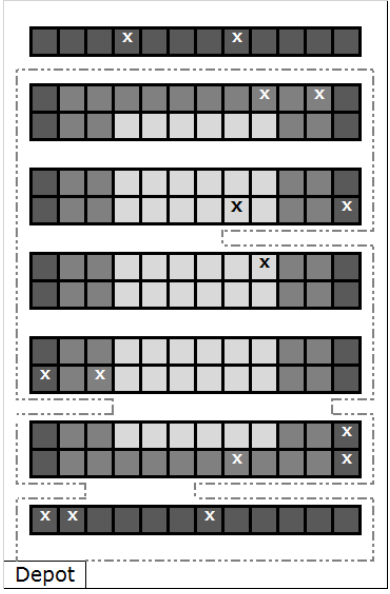

(c) Perimeter - largest gap.

Figure 6: Examples of good performing combinations of turnover based storage location assignment policies and routing policies.

ever, calculating optimal routes for each pick tour may require long computing times depending on the number of storage locations to visit in a pick tour. For single block layouts, the combined routing heuristic is able to approximate the optimal route (Roodbergen \& De Koster, 2001, Petersen \& Aase, 2004). The Lin-Kernighan-Helsaun routing heuristic (Helsgaun, 2000) has shown to provide excellent results to approximate the optimal route of order pickers for multiple warehouse blocks as well. Theys et al. (2010) reported an average optimality gap of $0.01 \%$ for the combination of within-aisle storage and LKH-routing.

The sizing of each storage class does not significantly influence the routing decision and resulting picking performance. Introducing a turnover based storage location assignment policy is more important than selecting the composition of storage classes (Manzini et al., 2007). Real-life characteristics have been incorporated while analyzing the relation between storage location assignment and routing, such as precedence constraints, which require certain products to be retrieved before other products due to weight restrictions, fragility, shape and size, or because of customer's preferences. Ignoring these precendence constraints can result in infeasible combinations of storage and routing policies in practice (Dekker et al. 2004). Furthermore, most studies analyze a 2D order picking area, while assuming 3D storage locations. Storage location assignment and routing policies should additionally account for differences in picking efficiency between moving in vertical and horizontal directions (Chan \& Chan, 2011). Another real-life characteristics that may be valuable to warehouses to increase order picking performance is the assignment of products to multiple storage locations. The effect of assigning fast moving SKUs to mul- 
tiple locations has not been analyzed so far. Especially in a dynamic context, multiple locations of a single SKU may have substantial impact on the routing problem, as orders can be more easily added to a pick list while the order picker has already started his pick tour.

\subsubsection{Order batching and Routing}

Publications examining the relation between order batching and order picker routing have mainly focused on solving the integrated problem of routing and batching, rather than considering interactions between batching and routing policies. As batching and routing are both operational decisions, these planning problems are particularly suitable for being solved in an integrated way. Efficient heuristic algorithms have been proposed for the simultaneous construction of batches and picking tours (Kulak et al., 2012, Cheng et al., 2015; Li et al., 2016. Lin et al., 2016), compared to combinations of more straightforward batching and routing policies.

Some innovative challenges and extensions related to the integrated batching and routing problem have been proposed in literature, such as dynamic picking systems (i.e. orders arrive in real time during the planning period), and sequencing batches in a picking system with a single order picker. While the above mentioned algorithms solving the integrated batching and routing problem focus on static picking systems, a stochastic polling model can be applied to a dynamic order picking system in which routes and batches dynamically change during a pick tour as a result of real time order arrival (Gong \& De Koster, 2008). Furthermore, including the sequence of batches to be retrieved by a single order picker in the batching and routing algorithm to meet order due times can significantly influence the service level (Chen et al., 2015). Moreover, as most warehouses require multiple order pickers to retrieve all orders, the integrated batching, routing and job assignment problem in a multiple order picker system would be of great value for practitioners. Especially in a dynamic context, the job assignment is very challenging as batches need to be assigned to multiple order pickers and the sequence of batches to be completed by each order picker should be determined to minimize the tardiness of orders. Real-life settings such as integrating batching and routing, while respecting precedence constraints of products, have motivated researchers to develop efficient solution methods incorporating these real-life constraints (Matusiak et al., 2014).

\section{Managerial Implications}

The results of this literature study show the importance of combining multiple order picking planning problems in order to efficiently manage order picking operations. This section discusses the practical implications of this research for warehouse managers. We provide guidelines how warehouse managers can solve combinations of tactical and operational planning problems to support decision making processes.

Results of the literature review show that the time horizon of the resulting decisions substantially influence the appropriate approach 


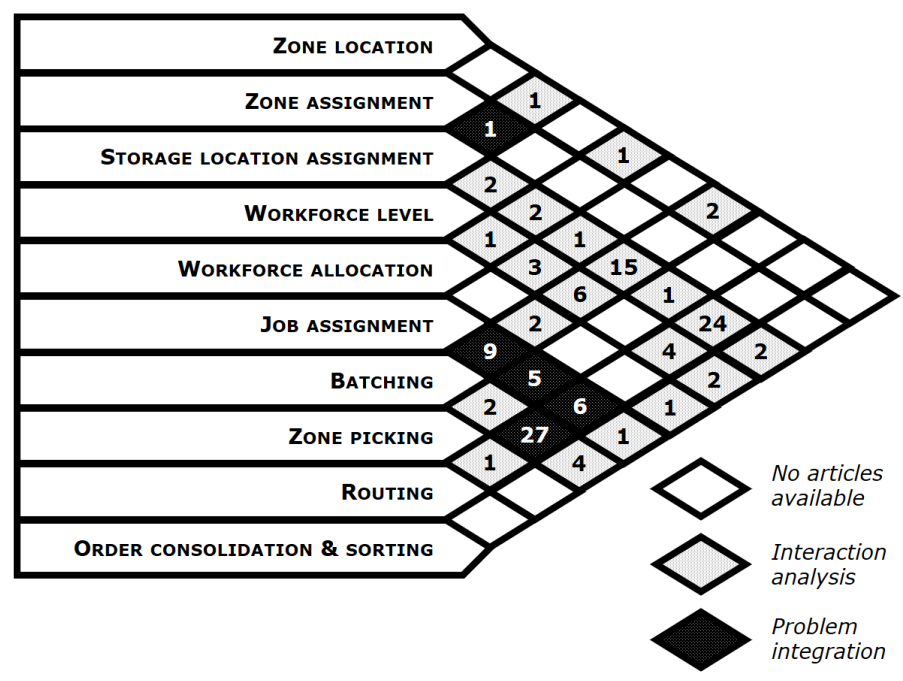

Figure 7: Best approach to solve each planning problems combination (numbers indicate the number of published articles considered in this review).

for solving combined order picking planning problems. On the one hand, problems could be combined by analysing interactions among specific predefined policies for each planning problem. On the other hand, two or more planning problems can be formulated and solved in an integrated manner. Figure 7 shows an overview of the approach applied in the majority of the considered articles to solve each combination of order picking planning problems, as well as the number of articles analyzing each combination.

Interaction analysis is most often applied to evaluate the joint effect of combining planning problems. Interaction analysis by means of analytical or simulation models has proven to be especially useful to evaluate the joint effect of planning problems with different time horizons of the resulting decision, such as storage location assignment and routing (e.g., Caron et al. (1998); Petersen \& Schmenner (1999); Chen et al. (2010); Dijkstra \& Roodbergen (2017)). The results of analytical and simulation models can be used by warehouse managers as decision support tool to design efficient order picking systems taking the interactions among order picking planning problems into account.

Problem integration is the appropriate approach to combine order picking planning problems with an operational time horizon, such as batching, routing and job assignment. Mathematical programming models are able to describe integrated planning problems, especially at an operational decision level, while accounting for real-life constraints (e.g., Matusiak et al. (2014, 2017); Zhang et al. (2017)). A wide range of heuristic 
algorithms have been proposed to provide fast and efficient solutions for the integrated problem of batching, routing and job assignment (e.g., (Chen et al., 2015; Scholz et al., 2017)) in accordance with practical needs: in case of short time horizons of decisions, fast and efficient algorithms are required to organize order picking operations.

Finally, we should note that the sample size for most planning problem combinations in Figure 7 is rather small . For example, the limited number of articles that combine job assignment and workforce allocation with the workforce level planning problem use interaction analysis, while an integrated model to solve a combination of these three planning problems seems to be more appropriate to support order picking operations. A model that provides the number of required order pickers and allocates this workforce, based on the expected workload, may be highly relevant to practice. Most combinations of tactical and operational order picking planning problems have not been widely investigated so far. However, articles in this review have proven the importance of combining these planning problems in order to optimize the order picking performance. Warehouse managers should be aware of the strong relation among order picking planning problems to optimize the performance and face the new market developments.

\section{Research Opportunities}

New market developments such as e-commerce, globalisation, increased customer expectations and new market regulations force warehouses to handle a growing number of orders in shorter time. Awareness of the influence of individual order picking planning problem on the overall performance is required to manage operations, resulting in enhanced customer service. This review paper differs from previous warehouse planning overviews by focusing on combinations of order picking planning problems. In this research, we provide an overview and classification of the relevant literature with respect to the research method used to combine order picking planning problems, the performance measurement to evaluate the combined problems, as well as with respect to the investigated combination of order picking planning problems.

Articles analyzing different tactical and operational order picking planning problems simultaneously are reviewed and classified in this study, with the aim of determining which planning problems are interdependent and how different individual planning problems are related to each other, as well as how warehouse managers can benefit from combining multiple order picking planning problems in order to face the new market developments. It does not make sense to integrate all planning problems due to the different time horizons of the resulting decisions. For example, integrating warehouse layout decisions and order batching does not seem relevant as batching is a daily decision, while layout is fixed in short and medium term. However, reviewing articles studying the effects of strategic planning problems on tactical and operational planning problems may provide relevant insights 
and general findings that could be used while deciding on strategic planning problems, such as the design of a new warehouse. Below we formulate research opportunities that will be highly relevant to practice and which are largely unexplored in literature combining tactical and operational order picking planning problems.

First, prior studies have strongly focused on reducing the order picking travel time. Future research could additionally focus on other performance measures (e.g., quality measures) and other aspects of order pick time (e.g., picker blocking). Quality measures, such as pick accuracy (i.e. the number of order picked without errors) and service level (i.e. number of orders picked on time), are rarely used as performance measure, despite the importance with respect to the customer service quality. Working under an increased time pressure as a result of the tight deadlines may increase the chance of pick errors. Moreover, the negative picker blocking effect, as a result of storage location assignment and batching policies that result in pick areas with high pick densities, is largely underestimated and could significantly impact the picking efficiency.

Next, the number of articles analyzing the relation among multiple order picking planning problems has increased strongly in the last decade. However, publications are concentrated on storage location assignment, order batching and routing. At a tactical level, the effects of zoning problems (i.e. zone location, zone assignment and zone picking) have received little research attention in combination with other planning problems, despite the fact that zoning can result in significant performance benefits. In a static context, the interdependencies among the zoning problems and other planning problems could be analyzed using analytical or simulation models. Incorporating these interaction effects while planning order picking operations may result in additional performance benefits.

Finally, at an operational level, there remains to be a need to integrate more planning problems and additionally account for real-life characteristics. Despite the importance of human resources in the labor-intensive environment of warehouses, few articles integrate workforce related planning problems (such as determining the daily workforce level, allocating the workforce across order picking areas and assigning jobs to order pickers) in other operational order picking planning problems. As warehouses deliver labor-intensive services to customers, the availability and performance of the human resources drive the service quality to customers and resulting order picking performance. For example, determining the workforce level in combination with the allocation of order pickers and the job assignment planning problem is a challenging opportunity for future research. Furthermore, prior studies assume strongly simplified order picking systems while integrating planning problems. The results of the classification clearly indicates the need for research that additionally accounts for real-life characteristics, such as real time order arrival, respecting precedence constraints and multiple locations of a single SKU, while analyzing combinations of order picking planning problems. Incorporating these real-life characteristics and constraints will make order picking research more valuable to practice. 


\section{References}

Bartholdi, J. J., Eisenstein, D. D., \& Foley, R. D. (2001). Performance of Bucket Brigades When Work Is Stochastic. Operations Research, 49, 710-719. doi 10.1287/opre.49.5.710.10609

Van den Berg, J. P. (1999). A literature survey on planning and control of warehousing systems. IIE transactions, 31, 751-762.

Caron, F., Marchet, G., \& Perego, A. (1998). Routing policies and COI-based storage policies in picker-to-part systems. International Journal of Production Research, 36, 713-732. doi 10. $1080 / 002075498193651$

Çelik, M., \& Süral, H. (2014). Order picking under random and turnover-based storage policies in fishbone aisle warehouses. IIE Transactions, 46, 283-300. doi 10.1080/0740817X.2013.768871

Chackelson, C., Errasti, A., Ciprés, D., \& Lahoz, F. (2013). Evaluating order picking performance trade-offs by configuring main operating strategies in a retail distributor: A Design of Experiments approach. International Journal of Production Research, 51, 6097-6109. doi $10.1080 / 00207543.2013 .796421$

Chan, F. T. S., \& Chan, H. K. (2011). Improving the productivity of order picking of a manual-pick and multi-level rack distribution warehouse through the implementation of class-based storage. Expert Systems with Applications, 38, 2686-2700. doi 10.1016/j.eswa.2010.08.058

Chen, C.-M., Gong, Y., De Koster, R., \& Van Nunen, J. (2010). A flexible evaluative framework for order picking systems. Production \& Operations Management, 19, 70-82. doi $10.1111 / \mathrm{j}$. $1937-5956.2009 .01047 . x$

Chen, F., Wang, H., Xie, Y., \& Qi, C. (2016). An ACO-based online routing method for multiple order pickers with congestion consideration in warehouse. Journal of Intelligent Manufacturing, 27, 389-408. doi $10.1007 / \mathrm{s} 10845-014-0871-1$

Chen, F., Wei, Y., \& Wang, H. (2017). A heuristic based batching and assigning method for online customer orders. Flexible Services and Manufacturing Journal, (pp. 1-46). doi 10.1007/ s10696-017-9277-7

Chen, T.-L., Cheng, C.-Y., Chen, Y.-Y., \& Chan, L.-K. (2015). An efficient hybrid algorithm for integrated order batching, sequencing and routing problem. International Journal of Production Economics, 159, 158-167. doi 10.1016/j.ijpe.2014.09.029

Cheng, C.-Y., Chen, Y.-Y., Chen, T.-L., \& Jung-Woon Yoo, J. (2015). Using a hybrid approach based on the particle swarm optimization and ant colony optimization to solve a joint order batching and picker routing problem. International Journal of Production Economics, 170, Part C, 805-814. doi 10.1016/j.ijpe.2015.03.021

Clarke, G. U., \& Wright, J. W. (1964). Scheduling of vehicles from a central depot to a number of delivery points. Operations research, 12, 568-581.

Davarzani, H., \& Norrman, A. (2015). Toward a relevant agenda for warehousing research: literature review and practitioners' input. Logistics Research, 8, 1-18. doi 10.1007/s12159-014-0120-1

De Koster, R., Le-Duc, T., \& Roodbergen, K. J. (2007). Design and control of warehouse order picking: A literature review. European Journal of Operational Research, 182, 481-501. doi 10. $1016 / j \cdot$ ejor.2006.07.009

De Koster, R., Le-Duc, T., \& Zaerpour, N. (2012). Determining the number of zones in a pick-andsort order picking system. International Journal of Production Research, 50, 757-771.

De Koster, R., Van der Poort, E., \& Wolters, M. (1999). Efficient orderbatching methods in warehouses. International Journal of Production Research, 37, 1479-1504.

Dekker, R., De Koster, R., Roodbergen, K. J., \& Van Kalleveen, H. (2004). Improving order-picking response time at Ankor's warehouse. Interfaces, 34, 303-313. doi 10.1287/inte.1040.0083

Dijkstra, A. S., \& Roodbergen, K. J. (2017). Exact route-length formulas and a storage location assignment heuristic for picker-to-parts warehouses. Transportation Research Part E: Logistics and Transportation Review, 102, 38-59. doi 10.1016/j.tre.2017.04.003 
Ene, S., \& Öztürk, N. (2012). Storage location assignment and order picking optimization in the automotive industry. The International Journal of Advanced Manufacturing Technology, 60, 787-797. doi 10.1007/s00170-011-3593-y.

Giannikas, V., Lu, W., Robertson, B., \& McFarlane, D. (2017). An interventionist strategy for warehouse order picking: Evidence from two case studies. International Journal of Production Economics, 189, 63-76. doi 10.1016/j.ijpe.2017.04.002

Gong, Y., \& De Koster, R. (2008). A polling-based dynamic order picking system for online retailers. IIE Transactions, 40, 1070-1082. doi 10.1080/07408170802167670

Gong, Y., \& De Koster, R. (2011). A review on stochastic models and analysis of warehouse operations. Logistics Research, 3, 191-205. doi 10.1007/s12159-011-0057-6

Gu, J., Goetschalckx, M., \& McGinnis, L. F. (2007). Research on warehouse operation: A comprehensive review. European Journal of Operational Research, 177, 1-21. doi 10.1016/j.ejor. 2006.02 .025

Guo, X., Yu, Y., \& De Koster, R. (2016). Impact of required storage space on storage policy performance in a unit-load warehouse. International Journal of Production Research, 54, 114. doi 10.1080/00207543.2015.1083624

Helsgaun, K. (2000). An effective implementation of the LinKernighan traveling salesman heuristic. European Journal of Operational Research, 126, 106-130. doi 10.1016/S0377-2217(99)00284-2

Henn, S. (2012). Algorithms for on-line order batching in an order picking warehouse. Computers E6 Operations Research, 39, 2549-2563. doi 10.1016/j.cor.2011.12.019

Henn, S. (2015). Order batching and sequencing for the minimization of the total tardiness in picker-to-part warehouses. Flexible Services and Manufacturing Journal, 27, 86-114. doi 10. 1007/s10696-012-9164-1.

Henn, S., Koch, S., \& Wäscher, G. (2012). Order Batching in order picking warehouses: a survey of solution approaches. In R. Manzini (Ed.), Warehousing in the Global Supply Chain (pp. 105-137). Springer London.

Henn, S., \& Schmid, V. (2013). Metaheuristics for order batching and sequencing in manual order picking systems. Computers E Industrial Engineering, 66, 338-351. doi 10.1016/j.cie.2013. 07.003

Henn, S., \& Wäscher, G. (2012). Tabu search heuristics for the order batching problem in manual order picking systems. European Journal of Operational Research, 222, 484-494. doi 10.1016/ j.ejor.2012.05.049

Hillier, F. S., \& Lieberman, G. J. (2010). Introduction to Operations Research. McGraw-Hill.

Ho, Y.-C., Su, T.-S., \& Shi, Z.-B. (2008). Order-batching methods for an order-picking warehouse with two cross aisles. Computers ES Industrial Engineering, 55, 321-347. doi $10.1016 / j . c i e$. 2007.12 .018

Ho, Y.-C., \& Tseng, Y.-Y. (2006). A study on order-batching methods of order-picking in a distribution centre with two cross-aisles. International Journal of Production Research, 44, 3391-3417.

Hong, S., Johnson, A. L., \& Peters, B. A. (2012a). Batch picking in narrow-aisle order picking systems with consideration for picker blocking. European Journal of Operational Research, 221, 557-570. doi $10.1016 / \mathrm{j} \cdot$ ejor.2012.03.045

Hong, S., Johnson, A. L., \& Peters, B. A. (2012b). Large-scale order batching in parallel-aisle picking systems. IIE Transactions, 44, 88-106. doi 10.1080/0740817X.2011.588994

Hong, S., Johnson, A. L., \& Peters, B. A. (2015). Quantifying picker blocking in a bucket brigade order picking system. International Journal of Production Economics, 170, Part C, 862-873. doi: $10.1016 /$ j.ijpe.2015.04.012

Hong, S., Johnson, A. L., \& Peters, B. A. (2016). Order batching in a bucket brigade order picking system considering picker blocking. Flexible Services and Manufacturing Journal, 28, 425-441. doi $10.1007 / \mathrm{s} 10696-015-9223-5$ 
Hong, S., \& Kim, Y. (2017). A route-selecting order batching model with the S-shape routes in a parallel-aisle order picking system. European Journal of Operational Research, 257, 185-196. doi $10.1016 /$ j.ejor.2016.07.017

Hsieh, L.-F., \& Huang, Y.-C. (2011). New batch construction heuristics to optimise the performance of order picking systems. International Journal of Production Economics, 131, 618-630. doi 10. $1016 / j$.ijpe.2011.02.006

Hsieh, L.-F., \& Tsai, L. (2006). The optimum design of a warehouse system on order picking efficiency. The International Journal of Advanced Manufacturing Technology, 28, 626-637. doi $10.1007 / \mathrm{s} 00170-004-2404-0$

Hwang, H., Oh, Y. H., \& Lee, Y. K. (2004). An evaluation of routing policies for order-picking operations in low-level picker-to-part system. International Journal of Production Research, 42, 3873-3889. doi 10.1080/00207540410001696339

Jane, C.-C., \& Laih, Y.-W. (2005). A clustering algorithm for item assignment in a synchronized zone order picking system. European Journal of Operational Research, 166, 489-496. doi 10. $1016 / j$. jor.2004.01.042

Jewkes, E., Lee, C., \& Vickson, R. (2004). Product location, allocation and server home base location for an order picking line with multiple servers. Computers 8 Operations Research, 31 , 623-636. doi 10.1016/S0305-0548(03)00035-2

Koo, P.-H. (2009). The use of bucket brigades in zone order picking systems. OR Spectrum, 31, 759-774. doi 10.1007/s00291-008-0131-x

Kulak, O., Sahin, Y., \& Taner, M. E. (2012). Joint order batching and picker routing in single and multiple-cross-aisle warehouses using cluster-based tabu search algorithms. Flexible Services and Manufacturing Journal, 24, 52-80. doi 10.1007/s10696-011-9101-8

Li, J., Huang, R., \& Dai, J. B. (2016). Joint optimisation of order batching and picker routing in the online retailers warehouse in China. International Journal of Production Research, 0, 1-15. doi: $10.1080 / 00207543.2016 .1187313$

Lin, C.-C., Kang, J.-R., Hou, C.-C., \& Cheng, C.-Y. (2016). Joint order batching and picker Manhattan routing problem. Computers \& Industrial Engineering, 95, 164-174. doi 10.1016/ j.cie.2016.03.009

Manzini, R., Gamberi, M., Persona, A., \& Regattieri, A. (2007). Design of a class based storage picker to product order picking system. The International Journal of Advanced Manufacturing Technology, 32, 811-821. doi 10.1007/s00170-005-0377-2

Marchet, G., Melacini, M., \& Perotti, S. (2015). Investigating order picking system adoption: a case-study-based approach. International Journal of Logistics Research and Applications, 18, 82-98. doi $10.1080 / 13675567.2014 .945400$

Matthews, J., \& Visagie, S. (2013). Order sequencing on a unidirectional cyclical picking line. European Journal of Operational Research, 231, 79-87.

Matusiak, M., De Koster, R., Kroon, L., \& Saarinen, J. (2014). A fast simulated annealing method for batching precedence-constrained customer orders in a warehouse. European Journal of Operational Research, 236, 968-977. doi 10.1016/j.ejor.2013.06.001

Matusiak, M., De Koster, R., \& Saarinen, J. (2017). Utilizing individual picker skills to improve order batching in a warehouse. European Journal of Operational Research, 263, 888-899. doi $10.1016 /$ j.ejor. 2017.05 .002

Öncan, T. (2015). MILP formulations and an iterated local search algorithm with tabu thresholding for the order batching problem. European Journal of Operational Research, 243, 142-155. doi $10.1016 /$ j.ejor.2014.11.025

Pan, J. C.-H., \& Wu, M.-H. (2012). Throughput analysis for order picking system with multiple pickers and aisle congestion considerations. Computers \& Operations Research, 39, 1661-1672.

Parikh, P. J., \& Meller, R. D. (2008). Selecting between batch and zone order picking strategies in a distribution center. Transportation Research Part E: Logistics and Transportation Review, 44, 696-719. doi $10.1016 / \mathrm{j} \cdot \mathrm{tre} .2007 .03 .002$ 
Petersen, C. G. (1997). An evaluation of order picking routeing policies. International Journal of Operations \& Production Management, 17, 1098-1111.

Petersen, C. G. (2000). An evaluation of order picking policies for mail order companies. Production and Operations Management, 9, 319-335.

Petersen, C. G. (2002). Considerations in order picking zone configuration. International Journal of Operations \&s Production Management, 22, 793-805. doi 10.1108/01443570210433553

Petersen, C. G., \& Aase, G. (2004). A comparison of picking, storage, and routing policies in manual order picking. International Journal of Production Economics, 92, 11-19. doi 10.1016/j.ijpe. 2003.09.006

Petersen, C. G., Aase, G., \& Heiser, D. R. (2004). Improving orderpicking performance through the implementation of classbased storage. International Journal of Physical Distribution $\varepsilon_{3}$ Logistics Management, 34, 534-544. doi 10.1108/09600030410552230

Petersen, C. G., \& Schmenner, R. W. (1999). An evaluation of routing and volume-based storage policies in an order picking operation. Decision Sciences, 30, 481-501. doi $10.1111 / \mathrm{j} \cdot 1540-5915$. 1999.tb01619.x

Pohl, L. M., Meller, R. D., \& Gue, K. R. (2009). Optimizing fishbone aisles for dual-command operations in a warehouse. Naval Research Logistics (NRL), 56, 389-403. doi 10.1002/nav.20355

Quader, S., \& Castillo-Villar, K. K. (2016). Design of an enhanced multi-aisle order-picking system considering storage assignments and routing heuristics. Robotics and Computer-Integrated Manufacturing, . doi 10.1016/j.rcim.2015.12.009

Roodbergen, K. J., \& De Koster, R. (2001). Routing methods for warehouses with multiple cross aisles. International Journal of Production Research, 39, 1865-1883. doi 10.1080/ 00207540110028128

Roodbergen, K. J., Vis, I., \& Don Taylor Jr, G. (2015). Simultaneous determination of warehouse layout and control policies. International Journal of Production Research, 53, 3306-3326. doi $10.1080 / 00207543.2014 .978029$

Rouwenhorst, B., Reuter, B., Stockrahm, V., Van Houtum, G. J., Mantel, R. J., \& Zijm, W. (2000). Warehouse design and control: Framework and literature review. European Journal of Operational Research, 122, 515-533. doi 10.1016/S0377-2217(99)00020-X

Ruben, R. A., \& Jacobs, F. R. (1999). Batch construction heuristics and storage assignment strategies for walk/ride and pick systems. Management Science, 45, 575-596.

Rubrico, J. I. U., Higashi, T., Tamura, H., \& Ota, J. (2011). Online rescheduling of multiple picking agents for warehouse management. Robotics and Computer-Integrated Manufacturing, 27, 62-71. doi 10.1016/j.rcim.2010.06.011

Scholz, A., Henn, S., Stuhlmann, M., \& Wäscher, G. (2016). A New Mathematical Programming Formulation for the Single-Picker Routing Problem. European Journal of Operational Research, 253, 68-84. doi $10.1016 /$ j.ejor.2016.02.018

Scholz, A., Schubert, D., \& Wscher, G. (2017). Order picking with multiple pickers and due dates Simultaneous solution of Order Batching, Batch Assignment and Sequencing, and Picker Routing Problems. European Journal of Operational Research, 263, 461-478. doi 10.1016/j.ejor.2017. 04.038

Scholz, A., \& Wäscher, G. (2017). Order Batching and Picker Routing in manual order picking systems: the benefits of integrated routing. Central European Journal of Operations Research, (pp. 1-30). doi 10.1007/s10100-017-0467-x

Shqair, M., Altarazi, S., \& Al-Shihabi, S. (2014). A statistical study employing agent-based modeling to estimate the effects of different warehouse parameters on the distance traveled in warehouses. Simulation Modelling Practice and Theory, 49, 122-135. doi 10.1016/j.simpat.2014.08.002

Sörensen, K., \& Glover, F. W. (2013). Metaheuristics. In Encyclopedia of operations research and management science (pp. 960-970). Springer. 
Staudt, F. H., Alpan, G., Mascolo, M. D., \& Rodriguez, C. M. T. (2015). Warehouse performance measurement: a literature review. International Journal of Production Research, 0, 1-21. doi $10.1080 / 00207543.2015 .1030466$

Theys, C., Bräysy, O., Dullaert, W., \& Raa, B. (2010). Using a TSP heuristic for routing order pickers in warehouses. European Journal of Operational Research, 200, 755-763. doi 10.1016/ j.ejor.2009.01.036

Tsai, C. Y., Liou, J. J. H., \& Huang, T. M. (2008). Using a multiple-GA method to solve the batch picking problem: considering travel distance and order due time. International Journal of Production Research, 46, 6533-6555. doi 10.1080/00207540701441947

Valle, C. A., Beasley, J. E., \& da Cunha, A. S. (2017). Optimally solving the joint order batching and picker routing problem. European Journal of Operational Research, 262, 817-834. doi 10. $1016 /$ j.ejor.2017.03.069

Van Gils, T., Ramaekers, K., Caris, A., \& Cools, M. (2016). The use of time series forecasting in zone order picking systems to predict order pickers workload. forthcomming in International Journal of Production Research, (pp. 1-14). doi 10.1080/00207543.2016.1216659

Van Nieuwenhuyse, I., \& De Koster, R. (2009). Evaluating order throughput time in 2-block warehouses with time window batching. International Journal of Production Economics, 121, 654664. doi $10.1016 /$ j.ijpe.2009.01.013

Won, J., \& Olafsson, S. (2005). Joint order batching and order picking in warehouse operations. International Journal of Production Research, 43, 1427-1442. doi 10.1080/00207540410001733896

Wruck, S., Vis, I. F. A., \& Boter, J. (2016). Risk control for staff planning in e-commerce warehouses. International Journal of Production Research, O, 1-17. doi 10.1080/00207543.2016.1207816

Yu, M., \& De Koster, R. (2008). Performance approximation and design of pick-and-pass order picking systems. IIE Transactions, 40, 1054-1069. doi 10.1080/07408170802167613

Yu, M., \& De Koster, R. (2009). The impact of order batching and picking area zoning on order picking system performance. European Journal of Operational Research, 198, 480-490. doi 10. $1016 / j \cdot$ ejor.2008.09.011

Yu, Y., De Koster, R. \& Guo, X. (2015). Class-Based Storage with a Finite Number of Items: Using More Classes is not Always Better. Production and Operations Management, 24, 1235-1247. doi $10.1111 /$ poms. 12334

Zhang, J., Wang, X., Chan, F. T. S., \& Ruan, J. (2017). On-line order batching and sequencing problem with multiple pickers: A hybrid rule-based algorithm. Applied Mathematical Modelling, 45, 271-284. doi $10.1016 / \mathrm{j}$.apm.2016.12.012 


\section{Appendix A. Overview of Order Picking Planning Problems}

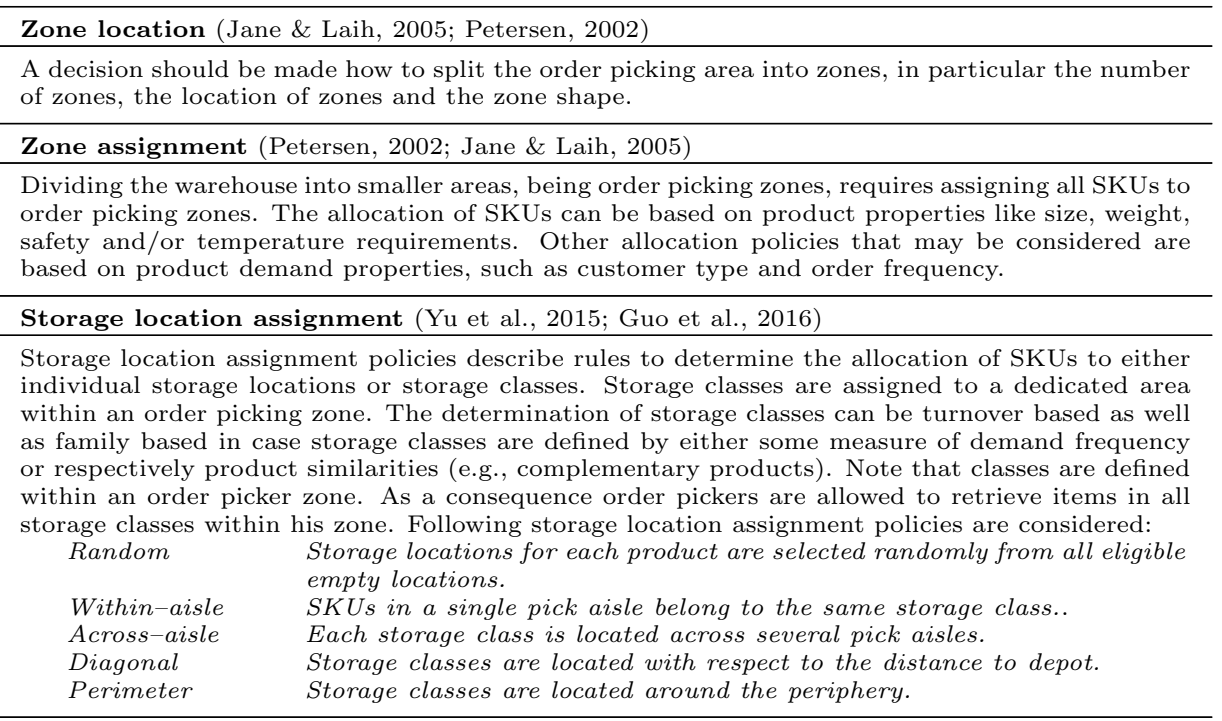

Workforce level (Van Gils et al. 2016)

Determining the daily number of order pickers to fulfill all customer orders.

Workforce allocation Van Nieuwenhuyse \& De Koster 2009 Van Gils et al. 2016

Allocating the available workforce across warehouse areas, including allocation across order picking zones and allocation across the picking and sorting area.

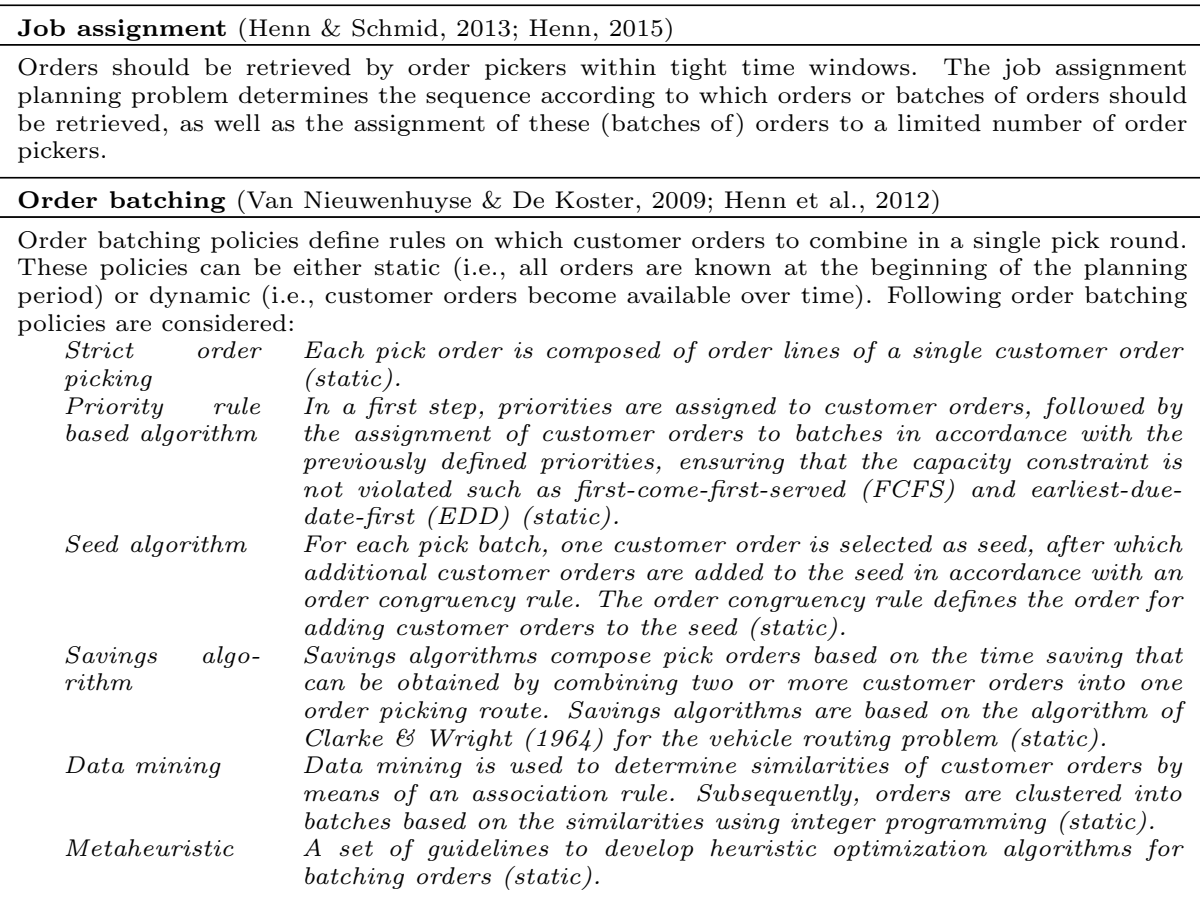


Variable time The order picker starts a picking tour whenever a particular number of window batch- customer orders have arrived (dynamic).

ing

Fixed time win- All customer orders arriving during a particular time interval are asdow batching signed to batches (dynamic).

Zone picking (De Koster et al. 2007, Parikh \& Meller 2008)

Zone picking policies define the flow of customers order through all order picking zones. Following zone picking policies are considered:

Sequential zon- Each order picker starts picking an order. When all parts of an order ing belonging to his order picking zone are picked, the order is passed to the next zone. Progressive zoning eliminates the requirement of a downstream sorter, however, at the expense of a reduced picking efficiency.

Parallel zoning All order pickers can start picking the same order, each order picker in his own zone. After picking, all orders should be consolidated through a sorting system.

Routing Petersen \& Schmenner 1999 Roodbergen \& De Koster 2001)

Routing policies define the sequence of storage locations that should be visited in each pick round to retrieve all items on a pick list. Following routing policies are considered:

Each order picker visits every pick aisle containing at least one pick location through the entire length.

Traversal Each order picker traverses every subaisle (i.e. the part of a pick aisle that is within one warehouse block) containing at least one pick location through the entire length.

Return Each order pickers enters and leaves each pick aisle containing at least one pick location from the same end.

Midpoint Each order picker enters an pick aisle only as far as the midpoint of an aisle and returns to leave the pick aisle from the same end.

Largest gap Each order picker enters a pick aisle only as far as the start of the largest gap within an aisle and returns to leave the pick aisle from the same end. The largest gap is defined as the maximum distance between any two adjacent pick locations within a single aisle, or the maximum distance between an aisle end and a pick location.

Combined Each order picker either traverses each pick aisle containing at least one pick location entirely or returns to leave the pick aisle from the same end.

Metaheuristic A set of guidelines to develop heuristic optimization algorithms for routing order pickers.

Order consolidation \& sorting (Van Nieuwenhuyse \& De Koster 2009

Order consolidation and sorting policies define the organization of the sorting activities in case of either batching or zoning. Following routing policies are considered:

Sort-while-pick Picked items are sorted on the pick cart per order during the picking

Pick-and-sort Sorting activities follow immediately after picking. 
Appendix B. Overview of the Reviewed Articles

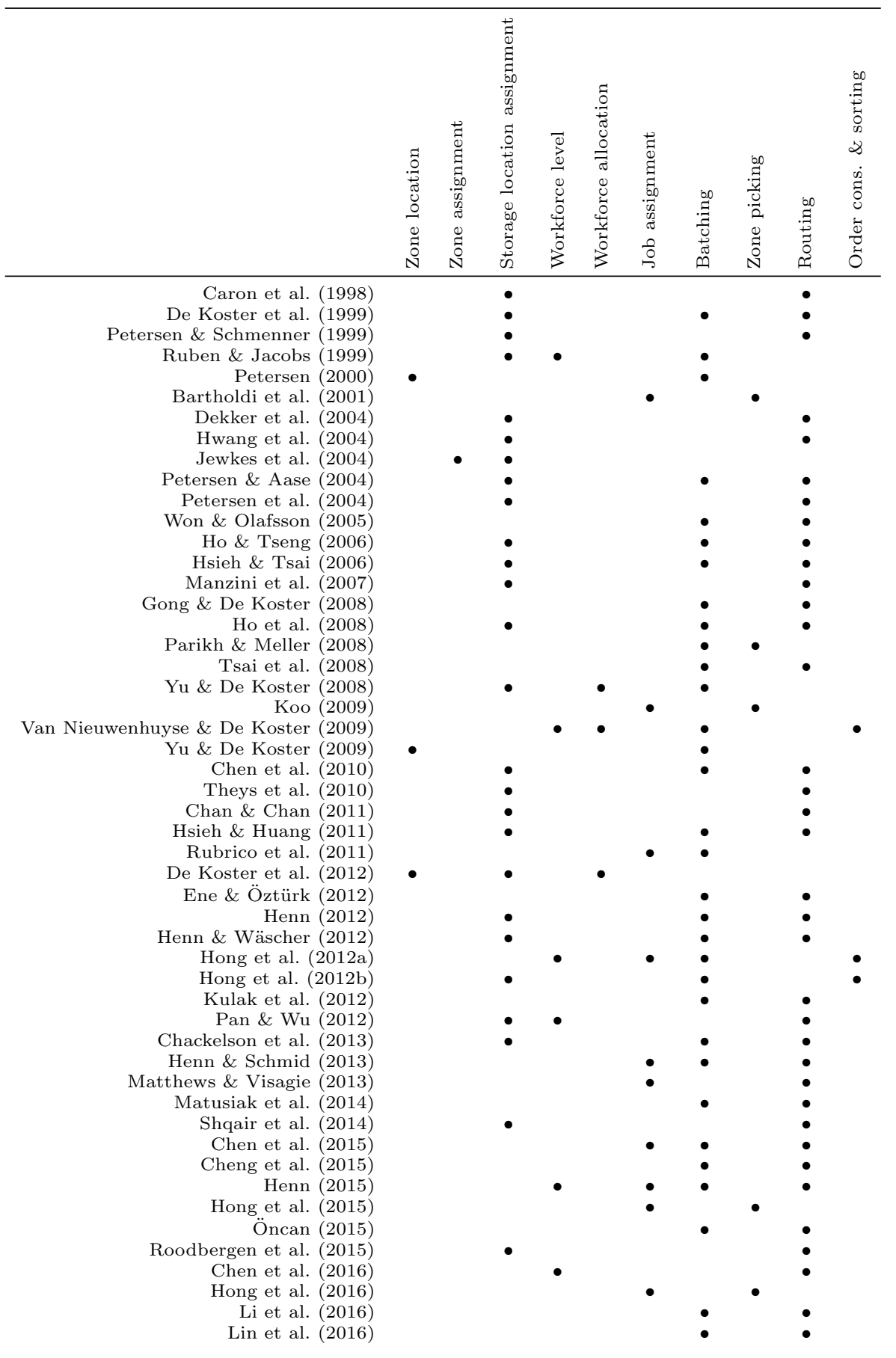




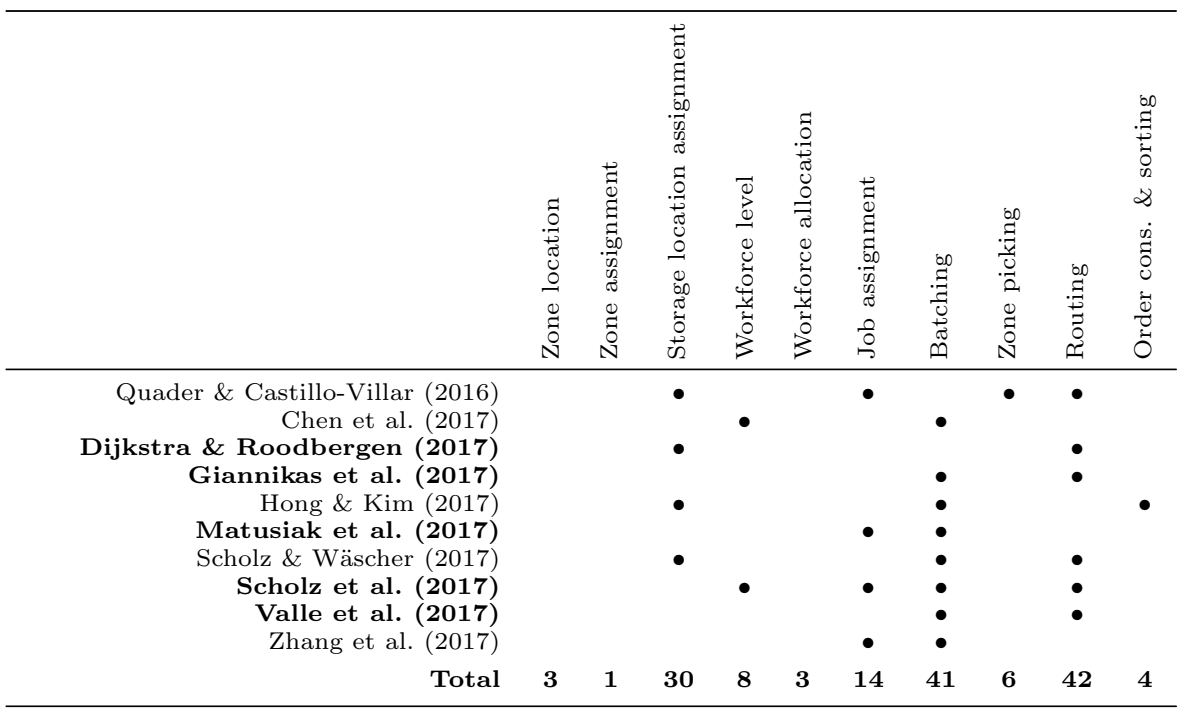

